\title{
CHEMOSPHERE
}

ELSEVIER

\section{Butyltin accumulation in the marine clam Mya arenaria: An evaluation of its suitability for monitoring butyltin pollution}

\author{
Rui-qiang Yang, Qun-fang Zhou, Gui-bin Jiang * \\ State Key Laboratory of Environmental Chemistry and Ecotoxicology, Research Center for Eco-Environmental Sciences, \\ Chinese Academy of Sciences, P.O. Box 2871, Beijing 100085, China
}

Received 3 June 2005; received in revised form 18 July 2005; accepted 31 July 2005

Available online 26 September 2005

\begin{abstract}
The use of Mya arenaria as a new sensitive biomonitor of butyltins pollution in the oceanic system was investigated. Field survey indicated that much higher levels of butyltin compounds were found in $M$. arenaria compared with the other species investigated. Using Mytilus edulis as a control organism, a 28 days exposure of tributyltin chloride (TBT) to $M$. arenaria for accumulation and subsequent 28 days breeding in clean seawater for elimination were conducted under laboratory conditions in order to confirm its high accumulation ability and characterize its kinetic behavior to TBT. Bioconcentration factor (BCF) of M. arenaria ranged from 15538 to 91800 after 28 days exposure. The rapid uptake and low rate to eliminate TBT of $M$. arenaria displayed first-order kinetics. M. arenaria shows potential as a new bioindicator to monitor TBT pollution in marine environment.
\end{abstract}

(C) 2005 Elsevier Ltd. All rights reserved.

Keywords: Mya arenaria; Mytilus edulis; Bioaccumulation; TBT; Biomonitor

\section{Introduction}

Tributyltin (TBT) has been used as a paint additive since the 1960s to prevent bio-fouling on ship hulls, marine platforms and fishing nets, which results in world-wide aquatic pollution. A number of studies have demonstrated the deleterious effect of TBT on nontarget marine organisms such as neogastropod imposex (Ellis and Pattisina, 1990; Michael, 2002), shell deformations of oysters (Axiak et al., 1995), sterilization of

\footnotetext{
* Corresponding author. Tel.: +86 10 62849334/62923566; fax: +86 $1062849179 / 62923563$.

E-mail address: gbjiang@mail.rcees.ac.cn (G.-b. Jiang).
}

Gastropoda (Oehlmann et al., 1996), Mytilus edulis with high morality due to butyltins (Beaumont and Budd, 1984). In spite of the restriction on the use of TBT based antifouling paints in several countries (Evans et al., 1995), butyltin compounds are still present in aquatic ecosystems, particularly in areas with intensive docking activities as well as possible industrial discharges. Up to now, there is no restriction on the use of organotin in China. Serious occurrence of butyltin compounds in Chinese aquatic ecosystem was evidenced by several works (Jiang et al., 2001; Zhou et al., 2001). It is essential to conduct a comprehensive and continuous monitoring survey of butyltins in the ocean environment to evaluate the fate and future trends of these contaminants. 
Biomonitors can be used to establish geographical distribution and temporal variations in the bioavailabilities of pollutants in the marine environment, offering time-integrated information of those portions of the total ambient contaminant load that are of direct ecotoxicological relevance. Marine mollusc was most often addressed as sensitive bioindicator for monitoring trace toxic substances in aquatic ecosystem due to their cosmopolitan distribution, sessile life style, easy sampling, tolerance to a large range of salinity, resistance to stress and high ability to concentrate various pollutants (Tanabe et al., 2000). In order to intraspecifically compare pollution status between geographical areas, many cosmopolitan biomonitors were established such as the mussels of the genera Mytilus and Perna, the oysters Ostrea and Crassostrea, barnacles like Balanus amphitrite and Tetraclita squamosa, etc. (Rainbow, 1995). However, it was a challenging task to find and establish a new sensitive biomonitor existing in aquatic system to indicate aquatic pollution.

Individual organism responds differently to certain pollutants because of its different uptake and elimination way. Wide investigation of TBT in Chinese seafood in the previous work has demonstrated high levels of TBT in Mya arenaria tissues, which suggested this organism might have stronger ability to accumulate TBT from water (Zhou et al., 2003). A field survey was carried out herein and butyltins contents in various species including bivalves and snails further confirmed the high butyltin accumulation ability of $M$. arenaria. In order to assess the value of $M$. arenaria as an indicator of aquatic TBT pollution, an experiment of 28 days exposure in several TBT concentrations and further elimination in clean seawater was carried out. Meanwhile, M. edulis, which was a most often used organism to indicator TBT pollution in aquatic systems was introduced for comparative study. Kinetic parameters of accumulation and elimination, accumulation characteristics, and the tissue distribution were also recognized in this paper.

\section{Materials and methods}

\subsection{Apparatus}

A GC-9A gas chromatograph (Shimadzu, Japan) equipped with a laboratory-made flame photometric detector using quartz surface-induced luminescence (QSIL-FPD) was used during the experiments. Butyltin compounds were base-lined separated in a HP-1 capillary column $(25 \mathrm{~m} \times 0.32 \mathrm{~mm}$ internal diameter $\times 0.17 \mu \mathrm{m}$ film thickness) with oven temperature increased from $100{ }^{\circ} \mathrm{C}$ (held for $1 \mathrm{~min}$ ) to $200{ }^{\circ} \mathrm{C}$ (held for $10 \mathrm{~min}$ ) at $5^{\circ} \mathrm{C} / \mathrm{min}$. The temperatures of the injector and the detector were maintained at 220 and
$160{ }^{\circ} \mathrm{C}$, respectively. High pure nitrogen was used as carrier gas and kept at the pressure of $0.26 \mathrm{MPa}$ on the column head. The flow rates of hydrogen and air were 260 and $90 \mathrm{ml} / \mathrm{min}$, respectively. A $394 \mathrm{~nm}$ sulfur interference filter was used for the measurement and a SC1100 PC data processing system recorded all the chromatograms.

\subsection{Standards and reagents}

The standards including tetrabutyltin (TeBT, 96\%), Tributyltin chloride (TBT, 90\%), dibutyltin dichloride (DBT, 97\%) and monobutyltin trichloride (MBT, 97\%) were purchased from Acros Organics (New Jersey, USA). The stock solutions were obtained by dissolving the accurately weighed TeBT, TBT, DBT and MBT into methanol to adjust the concentrations of $1 \mathrm{mg} \mathrm{Sn} / \mathrm{ml}$, respectively. The $\mathrm{pH}$ values of 2 controlled by concentrated $\mathrm{HCl}$ ensured the stability of the stock solutions. Working standard solutions were obtained by gradually diluting the stock solutions to the desired concentrations. All solutions were stored at $4{ }^{\circ} \mathrm{C}$ in refrigerator. The Grignard reagent of $n$-propylmagnesium bromide ( $n$-PrMgBr, $2.0 \mathrm{~mol} / \mathrm{l}$ ) was laboratory-prepared according to the methods (Zhou et al., 1999). All reagents used were of analytical grade or better. Glassware was rinsed with double-distilled water, decontaminated in 1:1 nitric acid solution over $8 \mathrm{~h}$ and then rinsed again.

\subsection{Field sampling}

Fig. 1 shows the five sampling sites for molluscs. These sampling sites are located in the northeast of China along the Bohai Sea, where heavy industry and fishing are relatively high developed. Possible serious

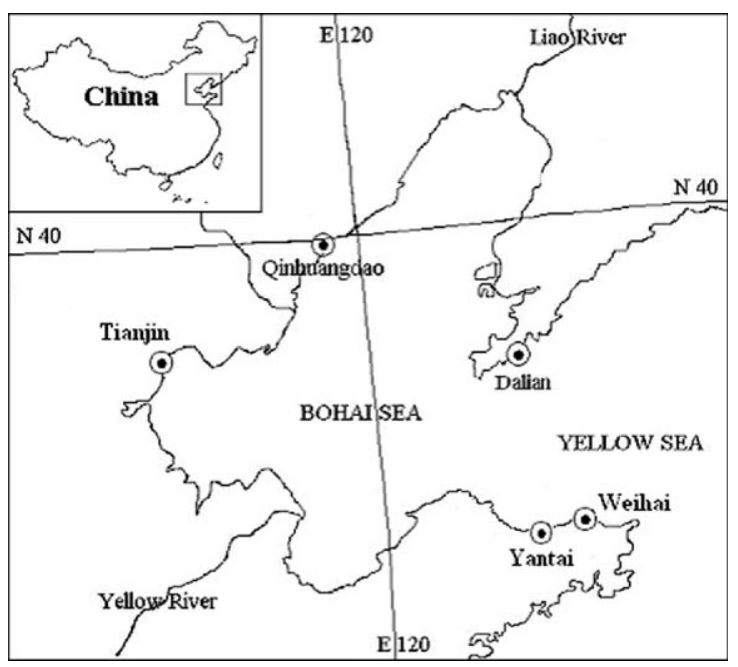

Fig. 1. Sampling sites of molluscs collected from the Bohai Sea. 
environmental pollution is thought to occur in this semienclosed aquatic system. The samples including several kinds of bivalves and snails were collected during July-August, 2002. Different species were identified according to the catalog of marine molluscs provided by Qi et al. (1989) and Zhao et al. (1982). The samples were kept in polyethylene bags, and frozen in an icebox during transportation. The samples were shucked and the soft tissues were thoroughly rinsed with de-ionized water and then blended to homogenate. The homogenate were stored at $-20{ }^{\circ} \mathrm{C}$ in glass bottles until analysis.

\subsection{Laboratory simulation study}

M. arenaria (shell length $63-78 \mathrm{~mm}$ ) and $M$. edulis (shell length $39-52 \mathrm{~mm}$ ) were collected from clean sites in Weihai (Fig. 1) in October, 2002. They were acclimated in the laboratory condition: $15 \pm 1{ }^{\circ} \mathrm{C}, 28 \pm 2 \%$ o salinity for 7 days prior to the exposure experiments. The healthy individuals were selected and randomly divided into four groups with 25 organisms of each species raised in the same tank containing 301 seawater. Three TBT nominal levels were 50, 200 and $800 \mathrm{ng} \mathrm{Sn/1} \mathrm{and}$ the exposure test lasted for 28 days. Another 28 days was subsequently used for depuration test in clean seawater. The organisms in the control group were kept under the similar condition as the exposure groups except that no TBT was introduced. The water was renewed every $24 \mathrm{~h}$, gently aerated, and the animals kept unfed throughout the experiment. Two individuals of each species were sampled from each group every 7 days for butyltin analysis. They were then shucked and washed with de-ionized water, carefully dried with paper towel and dissected into several parts including the muscles, waterspout, gills and viscera. All samples were kept frozen at $-20^{\circ} \mathrm{C}$ before analysis.

\subsection{Analytical procedure}

The analytical procedure was carried out according to the method described by Zhou et al. (2001). Briefly, after the addition of a suitable amount of TeBT as internal standard to the accurately weighed sample, acidification with $\mathrm{THF}-\mathrm{HCl}$ solution was followed. Extraction with $0.01 \%$ tropolone-hexane, concentration by a rotary evaporator, derivation with Grignard reagent and purification by anhydrous $\mathrm{Na}_{2} \mathrm{SO}_{4}$ and florisil-gel column were subsequently performed to obtain the suitable samples for GC-QSIL-FPD analysis. The concentrations of butyltins were quantitatively determined by the internal standard method. The correlation coefficients $(r)$ of calibration curves of butyltins were all higher than 0.998 . The analytical method was confirmed by determination of certified reverence material (CRM477, dry mussel tissue). The determination errors of MBT, DBT and TBT were $-8 \%,-5 \%$ and $-3 \%$, respectively. The relative standard derivation (RSD) values with five repeated measurements ranged from $9 \%$ to $13 \%$. Detection limit (assigned 3 times signal/noise) of TBT, DBT, MBT were 2.8, 3.2, $2.5 \mathrm{ng} \mathrm{Sn} / \mathrm{g}$ wet weight, respectively. These parameters confirmed the feasibility of the analytical protocols herein in the determination of butyltin compounds in molluscs. Procedural blanks were processed with every batch of eight samples, they were all free from organotin contamination or other interferences.

\subsection{Kinetic model}

The accumulation and depuration kinetics of TBT in the organisms were studied by the following kinetic model (formula 1) (Laughlin et al., 1986).

$\frac{\mathrm{d} C_{\mathrm{t}}}{\mathrm{d} t}=K_{\mathrm{u}} C_{\mathrm{w}}-K_{\mathrm{d}} C_{\mathrm{t}}$

where $C_{\mathrm{t}}=$ tissue concentration $(\mu \mathrm{g} / \mathrm{g} \mathrm{dw}) ; C_{\mathrm{w}}=$ water concentration $(\mathrm{ng} / \mathrm{l}) ; K_{\mathrm{u}}=$ rate constant of uptake; $K_{\mathrm{d}}=$ rate constant of depuration.

For accumulation procedure, $K_{\mathrm{d}}$ can be neglected, integration with $C_{\mathrm{w}}$ as a constant yields:

$C_{\mathrm{t}}=K_{\mathrm{u}} C_{\mathrm{w}} t+C_{\mathrm{t} 0}$

By linear regression of $C_{\mathrm{t}}$ vs. $t$, value of $K_{\mathrm{u}}$ can be obtained.

For depuration procedure, assuming $C_{\mathrm{w}}=0$, thus, integration of formula 3 :

$\frac{\mathrm{d} C_{\mathrm{t}}}{\mathrm{d} t}=-K_{\mathrm{d}} C_{\mathrm{t}}$

yields

$\ln C_{\mathrm{t}}=-K_{\mathrm{d}} t+\ln C_{\mathrm{t} 0}$

Values of $K_{\mathrm{d}}$ can be calculated by linear regression of $\ln C_{\mathrm{t}}$ vs. time.

The biological half-life $t_{1 / 2}$ is described as follows (Niimi, 1987):

$t_{1 / 2}=\frac{\ln 2}{k_{\mathrm{d}}}$

\section{Results}

\subsection{Field survey}

Total of 57 samples including 20 different species collected from the five sites including Dalian, Qinhuangdao, Tianjin, Yantai and Weihai were analyzed. The concentrations of butyltin compounds (mono-, di-, tributyltin) in all the samples were determined by the procedure as described above. The concentration of butyltins ranged from below the detection limits to $993.9 \mathrm{ng} \mathrm{Sn} / \mathrm{g}$ wet weight. The highest butyltin content was found in 
M. arenaria sample from Dalian. Obvious differences in butyltins accumulation existed in different species from the same sites. According to the results obtained, it was easy the butyltin contents in the sample of $M$. arenaria were all much higher than the other sampled species. For instance, in Weihai sites, the sample of Neverita didyma contained no detectable butyltins, while in $M$. arenaria sample, the level of butyltin compound was up to $259.2 \mathrm{ng} \mathrm{Sn} / \mathrm{g}$. Comparison of butyltin levels in 12 samples from Dalian, chosen as a typical example, clearly showed that $M$. arenaria had relatively higher ability of butyltin of butyltin accumulation than other species (Fig. 2). In addition, other species such as Rapana venosa, Modiolus elongates, Solen grandis, Standella capillacea, Clinocartium, Dosinia gibba, Solen gracilis, Scapharca broughtonii were also analysed. Similar results were obtained, indicating $M$. arenaria might have stronger ability to accumulate butyltins from seawater.

\subsection{Accumulation and depuration tests}

Fig. 3 illustrated the trend of TBT uptake in the two bivalves at several exposure concentrations and subsequent depuration following the return to clean seawater. The tissue burdens of TBT increased gradually with the increase of exposure concentrations and exposure time. The initial average tissue concentration of TBT in the M. arenaria and M. edulis were $0.19,0.045 \mu \mathrm{g} \mathrm{Sn} / \mathrm{g}$ dry weight $(\mathrm{dw})$, respectively. There were no significant changes for the two bivalves in the control group throughout the experiments. The accumulation equilibrium didn't seem to reach for both bivalves during 28 days' exposure. The highest TBT concentrations in $M$. arenaria and $M$. edulis were 12.43 and $1.45 \mu \mathrm{g} \mathrm{Sn} / \mathrm{g}$ $\mathrm{dw}$, respectively, in the exposure tests.
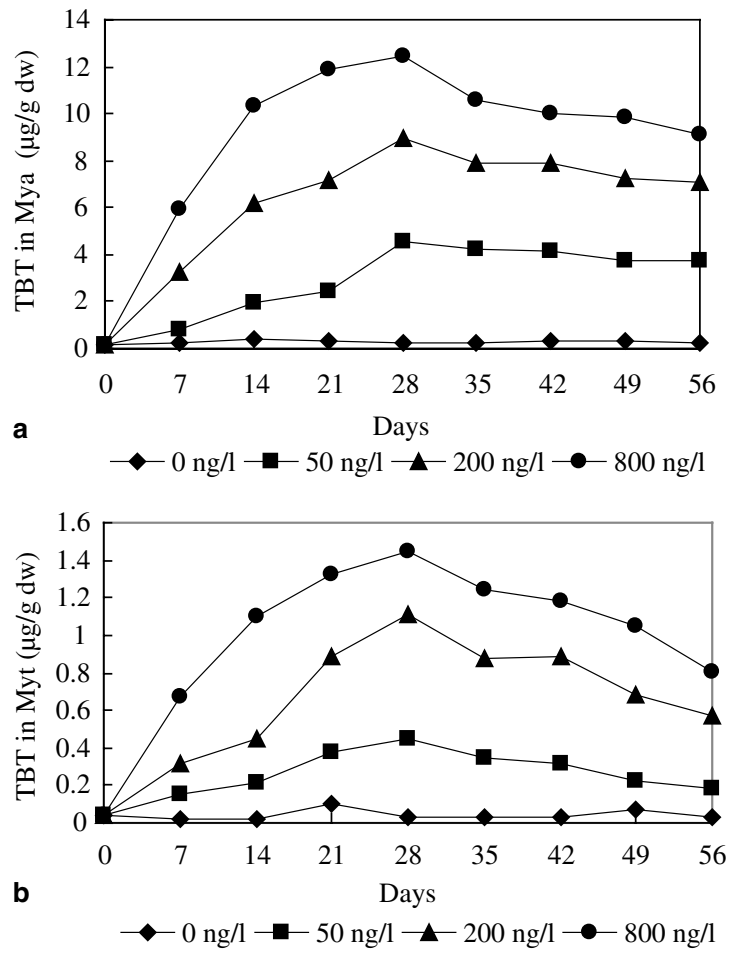

Fig. 3. Accumulation and depuration of TBT in bivalves under laboratory conditions. (a) Mya arenaria and (b) Mytilus edulis.

A first-order kinetic model was used to describe the uptake and depuration of contaminants into and from aquatic organisms (Yamada and Takayanagi, 1992). The related parameters are listed in Tables 1 and 2. The accumulation rate constant $K_{\mathrm{u}}$ ranged between 0.54 and 2.97 for M. arenaria and from 0.062 to 0.30 for M. edulis, respectively. $\mathrm{BCF}$ can usually be estimated from the rate

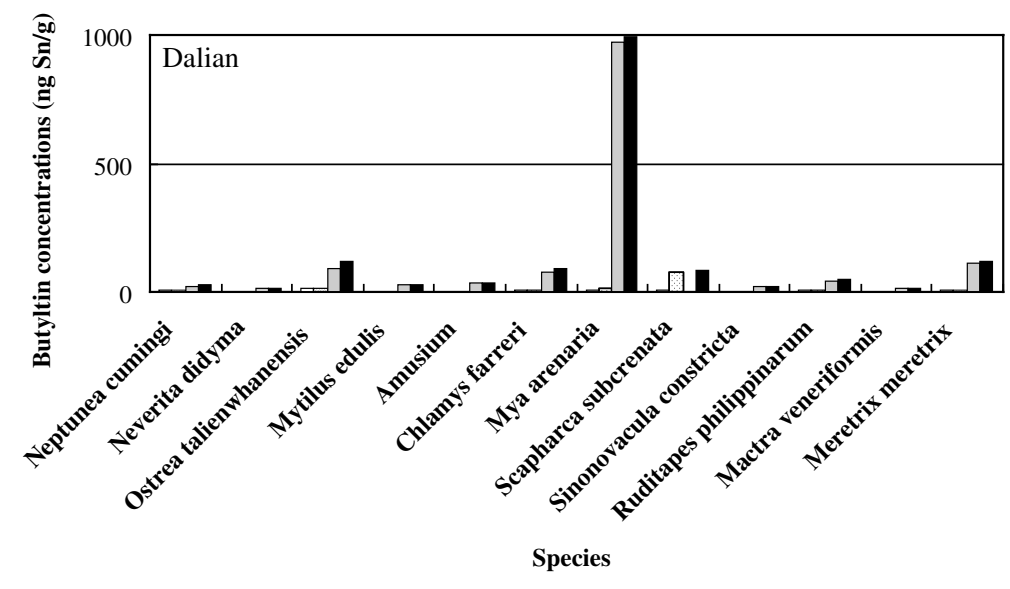

$\square$ Monobutyltin $\square$ Dibutyltin $\square$ Tributyltin $\square$ T-butyltins

Fig. 2. Comparison of butyltin levels in different species from Dalian. 
Table 1

Kinetic parameters of Mya arenaria (Mya) and Mytilus edulis (Myt) exposed to several levels of TBT for 28 days

\begin{tabular}{|c|c|c|c|c|c|c|}
\hline \multirow[t]{2}{*}{$\begin{array}{l}\text { TBT concentrations } \\
(\mathrm{ng} \mathrm{Sn} / \mathrm{l})\end{array}$} & \multicolumn{2}{|l|}{$K_{\mathrm{u}}{ }^{\mathrm{a}}$} & \multicolumn{2}{|l|}{$\mathrm{BCF}^{\mathrm{b}}$} & \multicolumn{2}{|c|}{$\begin{array}{l}\text { Correlation coefficient }(r) \text { and standard deviation } \\
\text { (SD) }(n=5 ; P<0.05)\end{array}$} \\
\hline & Mya & Myt & Mya & Myt & Mya & Myt \\
\hline 50 & 2.97 & 0.30 & 91800 & 9000 & $r=0.969, \mathrm{SD}=0.48$ & $r=0.989, \mathrm{SD}=0.028$ \\
\hline 200 & 1.53 & 0.19 & 44800 & 5550 & $r=0.980, \mathrm{SD}=0.79$ & $r=0.988, \mathrm{SD}=0.076$ \\
\hline 800 & 0.54 & 0.062 & 15538 & 1813 & $r=0.937, \mathrm{SD}=2.07$ & $r=0.959, \mathrm{SD}=0.19$ \\
\hline
\end{tabular}

${ }^{\mathrm{a}} K_{\mathrm{u}}$, accumulation rate constant $\left(\mathrm{g} \mathrm{g}^{-1} \mathrm{day}^{-1}\right)$.

b BCF, bioconcentration factor calculated by final tissue TBT concentration (ng/g dw) after 28 days' exposure divided with water TBT concentration (ng $\mathrm{Sn} / \mathrm{l})$.

Table 2

Kinetic parameters of Mya arenaria and Mytilus edulis during the depuration experiments

\begin{tabular}{llllll}
\hline Species & $\begin{array}{l}\text { Initial TBT } \\
(\mu \mathrm{g} \mathrm{Sn} / \mathrm{g} \mathrm{dw})\end{array}$ & $\begin{array}{l}\text { Final TBT } \\
(\mu \mathrm{g} \mathrm{Sn} / \mathrm{g} \mathrm{dw})\end{array}$ & $K_{\mathrm{d}}{ }^{\mathrm{a}}$ & $\begin{array}{l}t_{1 / 2} \\
(\text { days })\end{array}$ & $\begin{array}{l}\text { Correlation coefficient }(r) \\
\text { and standard deviation }(\mathrm{SD}) \\
(n=5 ; P<0.05)\end{array}$ \\
\hline Mya arenaria & 4.59 & 3.74 & 0.0098 & 71 & $r=0.987, \mathrm{SD}=0.024$ \\
& 8.96 & 7.08 & 0.008 & 87 & $r=0.953, \mathrm{SD}=0.032$ \\
Mytilus edulis & 12.43 & 9.14 & 0.0074 & 94 & $r=0.938, \mathrm{SD}=0.046$ \\
& 0.45 & 0.18 & 0.0328 & 21 & $r=0.956, \mathrm{SD}=0.069$ \\
& 1.11 & 0.57 & 0.0227 & 31 & $r=0.970, \mathrm{SD}=0.073$ \\
& 1.45 & 0.81 & 0.019 & 36 & $r=0.969, \mathrm{SD}=0.062$ \\
\hline
\end{tabular}

${ }^{\mathrm{a}} K_{\mathrm{d}}$, depuration rate constant $\left(\right.$ day $\left.^{-1}\right)$.

constants according to the kinetic models. In this study, a steady state was not observed, so the BCFs were obtained by the final tissue content $\left(C_{\mathrm{t}}, \mathrm{ng} / \mathrm{g} \mathrm{dw}\right)$ divided with the seawater concentration $\left(C_{\mathrm{w}}, \mathrm{ng} / \mathrm{l}\right)$ after 28 days exposure. The BCF data ranged from 15538 to 91800 (dw) for $M$. arenaria and from 1813 to 9000 (dw) for M. edulis, respectively. BCF data of the two bivalves decreased as TBT concentration in water increased.

During the depuration processes, the tissue TBT decreased quickly during the first 7 days, then exhibited a slower reduction with the depuration time increased (Fig. 3). This exponential decay trend of TBT concentration in tissues during depuration experiment indicated first-order kinetics (Gomez-Ariza et al., 1999). The tissue concentration did not return to their initial levels even after 28 days elimination time. The accumulation rate constant $\left(K_{\mathrm{u}}\right)$ of $M$. arenaria was different from its depuration rate constant $\left(K_{\mathrm{d}}\right)$ (as shown in Tables 1 and 2 ). The biological half-life of TBT elimination $\left(t_{1 / 2}\right)$ ranged from 71 to 94 days for $M$. arenaria and from 21 to 36 for M. edulis.

To study the metabolism of the organisms, the primary metabolites DBT and MBT were also determined in the tissues. For example, in $200 \mathrm{ng} \mathrm{Sn} / 1$ exposure group, the results showed that the breakdown products occurred but did not increase significantly with the increase of time for the two bivalves during the accumulation or depuration process (Fig. 4). As for M. arenaria, the amount of DBT and MBT never exceeded $11 \%$ of

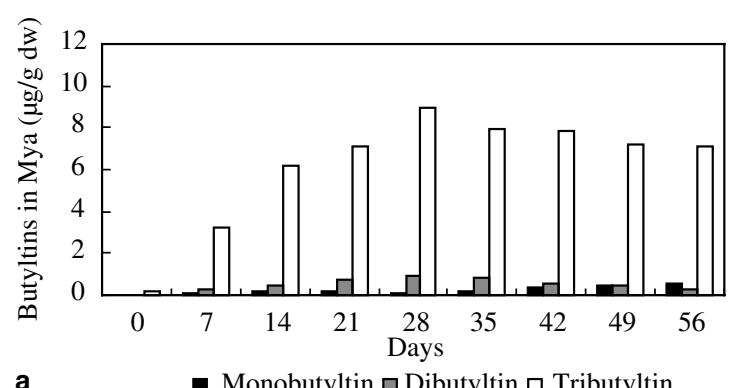

a

— Monobutyltin $\square$ Dibutyltin $\square$ Tributyltin

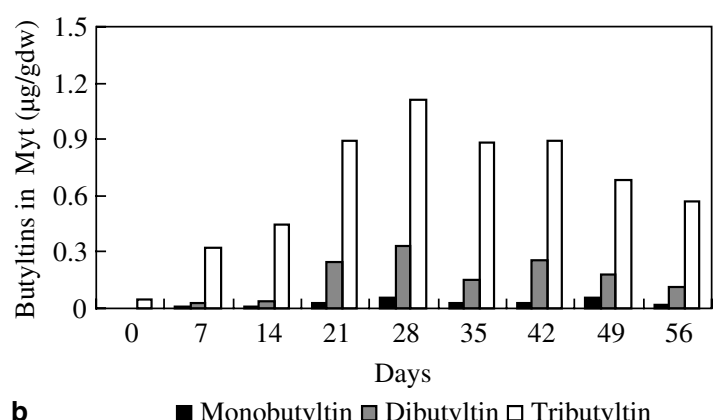

Fig. 4. Metabolites of TBT in the bivalves during exposure (200 ng Sn/l) and depuration experiments. (a) Mya arenaria and (b) Mytilus edulis.

the total butyltin compounds, whereas for $M$. edulis the percentages of degradation products occupied $0-26 \%$. 


\subsection{Distribution of TBT in bivalve tissues}

In order to investigate the distribution status of the pollutants in organism tissues, the bivalves exposed to $200 \mathrm{ng} \mathrm{Sn} / 1$ seawater were dissected and the butyltins in the main tissues were measured. $M$. arenaria was separated into four parts including muscles, waterspout, gills and viscera, while $M$. edulis was separated into two parts (muscles + waterspout, gills + viscera) because of its small body size. Variations of the TBT concentrations in each part were plotted with exposure and depuration time, which was depicted in Fig. 5. Much higher levels of TBT concentrations were found in the gills and viscera for the two bivalves, while lower amounts were detected in the muscles and waterspout tissues. Specifically, gills were the highest burden tissue for TBT with a value of $15.68 \mu \mathrm{g} \mathrm{Sn} / \mathrm{g} \mathrm{dw}$ for $M$. arenaria. During the depuration process, TBT levels in gills dropped at higher rates, while in muscles and waterspout tissues, TBT decreased at relatively lower rates.

\section{Discussion}

Based on the results of field survey, it indicated that most of the mollusc samples were contaminated with butyltin compounds, especially for TBT. Different species have different concentrations of butyltins. M. arenaria exhibited stronger accumulation ability for butyltin compounds compared with the other molluscs and it

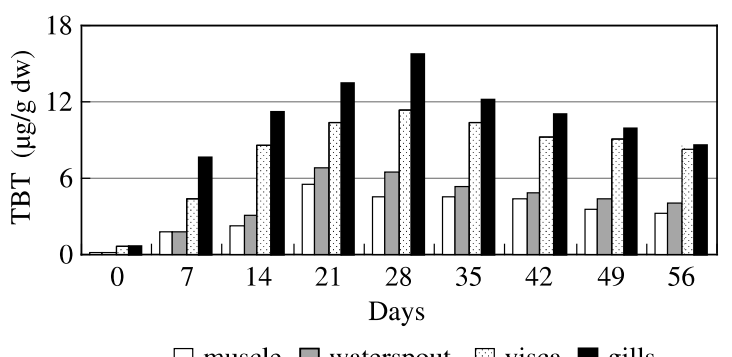

a

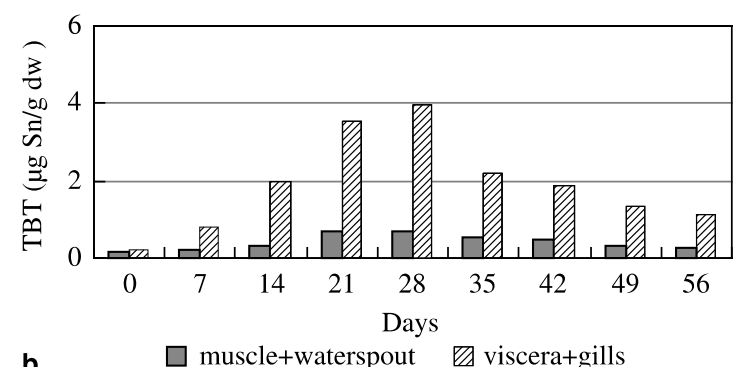

Fig. 5. TBT distribution in the tissues of the bivalves exposed to $200 \mathrm{ng} \mathrm{Sn} / 1$ for 28 days and returned to clean seawater for another 28 days. (a) Mya arenaria and (b) Mytilus edulis. could be a hopeful biomonitor of butyltin pollution in the ambient marine environment.

It is important to know the pollutants accumulation pattern of a selected biomonitor, incorporating an understanding the kinetics including the rates of uptake and elimination of the pollutant. This allows definition of the period over which the biomonitor reflects the ambient pollution levels. After a 28 days' exposure experiment with different TBT concentrations (spanning from 50 to $800 \mathrm{ng} \mathrm{Sn/l),} \mathrm{a} \mathrm{steady} \mathrm{state} \mathrm{was} \mathrm{not} \mathrm{observed}$ for both of the tested bivalves. The bivalves concentrated TBT from seawater exhibited typical first-order kinetics. The linear correlation coefficients $(r)$ between tissues and exposure time were all above 0.950 except for $M$. arenaria (0.937) in $800 \mathrm{ng} \mathrm{Sn/1} \mathrm{exposure} \mathrm{group.}$ The maximum tissue concentrations reached 12.43 and $1.45 \mu \mathrm{g} \mathrm{Sn} / \mathrm{g} \mathrm{dw}$ for $M$. arenaria and $M$. edulis, respectively; the maximal BCFs were 91800 and 9000 (dw) for $M$. arenaria and $M$. edulis, respectively. These results confirmed $M$. arenaria had stronger ability to concentrate TBT from seawater compared with $M$. edulis.

Many other studies about accumulation and depuration of TBT have been performed using various molluscs. Venerupis decussata (a marine clam) exposed to 81.4-2470 ng/l of TBT in a daily renewal protocol could reach a steady state within 40 days (Gomez-Ariza et al., 1999); the filter feeding Dreissena polymorha (a freshwater mussel) exposed to $80 \mathrm{ng} / 1$ of TBTCl under field conditions reached a steady state after 35 days (Van Slooten and Tarradellas, 1994); M. galloprovincialis (a marine mussels) under both field experiments exposed to $450 \mathrm{ng} / 1$ and a flow-through system exposed to 80 and $200 \mathrm{ng} / 1$ reached a steady state after 60 days (Vaikirs et al., 1987). Huang, using a flow through system, reported that TBT in tissues of $M$. edulis reached a steady state only when mussels were exposed to TBT concentration lower than $500 \mathrm{ng} / \mathrm{l}$ (Huang and Wang, 1995). Another study carried out under the lab experiment conditions with $M$. edulis showed no steady state was obtained either after 47 days of accumulation with $500 \mathrm{ng} / 1 \mathrm{TBT}$ seawater or after 30 days in the presence of contaminated phytoplankton (Laughlin et al., 1986). These time differences to a steady state may be caused by many factors such as test conditions (static renewal or flow though system; field or laboratory studies), and different species.

$\mathrm{BCF}$ reflects the ability of a particular organism to concentrate pollutants from ambient aquatic environment. High BCF is an important feature in selecting suitable indicators for pollution monitoring. However, comparison of $\mathrm{BCF}$ data from the literature is difficult because of the high variability of the results. Those discrepancies might result from the differences existing in the experiment types (field or laboratory studies), the test conditions, the various species, the feeding strategies and the exposure concentrations of TBT. Most of the 
BCF data from literatures reported on a wet weight basis and had to be changed into a consistent basis for comparison. With this caveat in mind, it was possible to compare the $\mathrm{BCF}$ s herein with those reported in the literatures. In this study, the higher BCF data came from the organisms exposed to the lower TBT concentration in seawater. The BCFs for $M$. arenaria ranged from 15538 to 91800 (dw) and was about eight times as high as that of M. edulis (ranged from 1813 to 9000). As it was known that the previously reported BCFs for marine biota were situated between 1000 and $980000(\mathrm{dw})$; most of the BCFs reviewed were between 1000 and $70000(\mathrm{dw})$. The reported highest BCF was 980000 (dw) by mussel $D$. polymorpha under field conditions after 35 days exposure (Van Slooten and Tarradellas, 1994). M. arenaria, a deposit feeder, could accumulate dissolved TBT not only via respiratory currents but also via ingested sediment particles during feeding. In the present study, the test organisms only concentrated TBT from seawater as no food and sediments were offered throughout the experiment. The exposure time was not long enough to reach a steady state, and the lab condition might be a bit worse than the field condition for bivalves' growth. The $\mathrm{BCF}$ data of $M$. arenaria are still much higher than those of other usual marine biota.

During the depuration processes, the exponential decay trend of TBT concentration in tissues with time indicated first-order kinetics. The accumulation rate constant $K_{\mathrm{u}}$ of $M$. arenaria were much higher than corresponding elimination rate constant $K_{\mathrm{d}}$. Concerning the half-lives $t_{1 / 2}$, which gives an indication of the persistence of the TBT in the bivalves, was 71-94 days for $M$. arenaria, whereas approximately 21-36 days for $M$. edulis in this study. This result accorded with the previously reported data. The half-life values of 14 days in $M$. edulis using exponential decay model (Laughlin et al., 1986), 26 days for D. polymorpha (Van Slooten and Tarradellas, 1994), 50 days for S. plana (Langston and Burt, 1991), approximately 100 days for Nucella lapillus (Bryan et al., 1987) were published, which could be comparable with that for $M$. arenaria in this study. These characteristics of depuration indicated that $M$. arenaria had a lower rate to eliminate TBT than other species. Therefore, M. arenaria could be more suitable for reflecting the long-term accumulation of TBT compared with M. edulis. As gill tissue of M. arenaria was very sensitive to variations of TBT concentration in water (Fig. 5), it might be used to indicate short-term fluctuations of this kind of pollutant.

An ideal biomonitor should fulfil several criteria. It should be sedentary, easy to identify, abundant, long lived, large enough to analysis, resistant to handing stress caused by laboratory studies, easy transplantation, tolerant of environmental variations in physicochemical parameters, etc. (Rainbow, 1995). M. arenaria belonged to lamellibranchia, eulamellibranchia, Myidae and usually located in intertidal zone and led an embedding life. It had long oval-shaped shell, thick chitin and yellow or filemot skin which was easy to identify. It was weighty and large enough (shell length of adults was up to $13 \mathrm{~cm}$ or more) to provide sufficient tissue for (individual) analysis. It widely distributed in the Bohai Sea and the Yellow Sea of China, east open ocean of Russia, Bering Strait, west ocean of north America and north ocean of Japan, Korea. These characteristics of M. arenaria showed a good precondition for its use as a biomonitor. It was notable that bioaccumulation, a chemical and biological procedure integrated by organism, could be quantitatively measured by chemical analysis. The extremely high level of TBT in $M$. arenaria showed that $M$. arenaria has stronger ability to accumulate or lower rate to metabolize this kind of environmental pollutants than other sampled species. Therefore, $M$. arenaria was a potential new biomonitor to indicate butyltin pollution in oceanic environment. Further work of field exposure study was still required to confirm the validity and feasibility of $M$. arenaria as a suitable biomonitor of butyltins pollution.

\section{Conclusion}

Based on the results from the field survey and laboratory study, it was concluded that $M$. arenaria had strong ability to accumulate TBT from aquatic environment and low rate to eliminate this kind of pollutants from its body. It also showed high tolerance of high body burden of butyltin compounds. This bivalve exhibited potential as a useful bioindicator of long-term butyltins pollution status in marine system, while its gill tissue might be used to indicate short-term fluctuations of this kind of pollution.

\section{Acknowledgements}

This work was supported by the National Natural Science Foundation of China (20137010).

\section{References}

Axiak, V., Sammut, M., Chircop, P., Vella, A., Mintoff, B., 1995. Laboratory and field investigations on the effects of organotin (tributyltin) on the oyster, Ostrea edulis. Sci. Total Environ. 171, 117-120.

Bryan, G.W., Gibbs, P.E., Bur, G.R., Hummerstone, L.G., 1987. The effects of tributyltin (TBT) accumulation on adult dog-whelks, Nucella lapillus: long-term field and laboratory experiments. J. Mar. Biol. Assess, (UK) 67, 525-544.

Beaumont, A.R., Budd, M.D., 1984. High mortality of the larvae of the common mussel at low concentrations of tributyltin. Mar. Pollut. Bull. 15, 402-405. 
Ellis, D., Pattisina, L.A., 1990. Worldwide neogastropod imposex: a biological indication of global TBT contamination? Mar. Pollut. Bull. 21, 248-253.

Evans, S.M., Leksono, T., Mckinnell, P.D., 1995. Tributyltin pollution: a diminishing problem following legislation limiting the use of TBT-based antifouling paints. Mar. Pollut. Bull. 30, 14-21.

Gomez-Ariza, J.L., Morales, E., Giraldez, I., 1999. Uptake and elimination of tributyltin in clams, Venerupis decussata. Mar. Environ. Res. 47, 399-413.

Huang, G., Wang, Y., 1995. Effects of tributyltin chloride on marine bivalve mussels. Water Res. 29, 1877-1884.

Jiang, G.B., Zhou, Q.F., Liu, J.Y., Wu, D.J., 2001. Occurrence of butyltin compounds in the waters of selected lakes, rivers and coastal environments from China. Environ. Pollut. 115, 81-87.

Langston, W.J., Burt, G.R., 1991. Bioavailability and effects of sediments-bound TBT in deposit-feeding clams, Scrobicularia plana. Mar. Environ. Res. 32, 61-77.

Laughlin, R.B., French, W., Guard, H.E., 1986. Accumulation of bis (tributyltin) oxide by the marine mussels Mytilus edulis. Environ. Sci. Technol. 20, 884-890.

Michael, B., 2002. Imposex and tributyltin contamination as a consequence of the establishment of a marina, and increasing yachting activities at Phuket Island, Thailand. Environ. Pollut. 117, 421-429.

Niimi, A.J., 1987. Biological half-lives of chemicals in fishes. Rev. Environ. Contam. Toxicol. 99, 1-46.

Oehlmann, J., Fioroni, P., Stroben, E., Markert, B., 1996. Tributyltin (TBT) effects on Oncinebrina aciculate (Gastropoda: Muricidae) imposex development, sterilization, sex change and population decline. Sci. Total Environ. 188, 205-223.

Qi, Z.Y., Ma, X.T., Wang, Z.R., Lin, G.Y., Xu, F.X., Dong, Z.Z., 1989. Mollusca of Huanghai and Bohai Sea. Agriculture Publishing House, Beijing.
Rainbow, P.S., 1995. Biomonitoring of heavy Metal availability in the marine environment. Mar. Pollut. Bull. 31, 183192.

Tanabe, S., Prudente, M.S., Kan-atireklap, S., Subramanian, A., 2000. Mussel watch: marine pollution monitoring of butyltins and organochlorines in coastal waters of Thailand, Philippines and India. Ocean \& Coastal Management 43, 819-839.

Van Slooten, K.B., Tarradellas, J., 1994. Accumulation, depuration and growth effects of tributyltin in the freshwater bivalve Dreissena Polymorpha under field conditions. Environ. Toxicol. Chem. 13, 755-762.

Vaikirs, A.O., Davidson, B.M., Seligman, P.F., 1987. Sublethal growth effects and mortality to marine bivalves from long-term exposure to tributyltin. Chemosphere 16, 201220.

Yamada, H., Takayanagi, K., 1992. Bioconcentration and elimination of bis (tributyltin) oxide (TBTO) and triphenyltin chloride (TPTC) in several marine fish species. Water Res. 26, 1589-1595.

Zhao, R.Y., Cheng, J.M., Zhao, D.D., 1982. Marine Mollusca Fauna of Dalian. Oceanic Publishing House, Beijing.

Zhou, Q.F., Jiang, G.B., Liu, J.Y., 2001. Small-scale survey on the contamination status of butyltin compounds in seafood collected from seven Chinese cities. J. Agric. Food Chem. 49, 4287-4291.

Zhou, Q.F., Jiang, G.B., Qi, D.Q., 1999. Synthesis and application of propylmagnesium bromide Grignard reagent in derivation of butyltin compounds. Chinese J. Anal. Chem. 27, 1197-1199.

Zhou, Q.F., Li, Z.Y., Jiang, G.B., Yang, R.Q., 2003. Preliminary investigation of a sensitive biomarker of organotin pollution in Chinese coastal aquatic environment and marine organisms. Environ. Pollut. 125, 301304. 